\title{
DESIGUALDADE ECONÔMICA E DIREITOS POLÍTICOS NA TEORIA DA JUSTIÇA DE RAWLS: Uma Análise a Partir de Thomas Scanlon
}

\author{
http://dx.doi.org/10.21527/2176-6622.2021.55.252-264
}

Recebido em: 12/2/2020

Modificações solicitadas em: 20/4/2020

Aceito em: 20/7/2020

\author{
Sandra Suely Moreira Lurine Guimarães \\ Autora correspondente. Faculdade Faci Wyden - Wyden Educacional. Travessa Tupinambás, 461 \\ - Batista Campos. CEP 66025-610. Belém/PA, Brasil. http://lattes.cnpq.br/5446022928713407. \\ https://orcid.org/0000-0002-8835-7420. sandralurine@yahoo.com.br \\ Heitor Moreira Lurine Guimarães \\ Universidade Federal do Pará. Belém/PA, Brasil.
}

\section{RESUMO}

O presente artigo, de natureza bibliográfica, pretende problematizar a maneira como a questão das desigualdades socioeconômicas e dos direitos políticos são tratados na teoria da justiça originalmente formulada por John Rawls. Sabe-se que Rawls, na década de 70, revolucionou os debates sobre justiça distributiva com a formulação da teoria que ficou conhecida como equidade, que se baseia na proposição de dois princípios de justiça, o primeiro tendo prioridade em relação ao segundo, destinados a reger a estrutura básica da sociedade. Muito recentemente, contudo, uma série de desafios teóricos à tradição liberal igualitária, da qual Rawls é um grande expoente, foi lançada por Thomas Scanlon, em sua proposta de atribuir à igualdade um valor intrínseco. O objetivo deste trabalho é mostrar como uma das questões levantadas por Scanlon, referente à questão da participação política, pode ser capaz de comprometer seriamente a proposta original de Rawls de tal forma que a distribuição indicada como justa pelos próprios princípios acabaria por quebrar a prioridade estabelecida entre eles. Primeiramente, faremos um estudo sistemático de como Rawls elabora seus dois princípios de justiça e qual o lugar da igualdade dentro deles, com ênfase para os elementos relevantes para a análise posterior. Em seguida, tentaremos demonstrar, a partir do ponto de vista oferecido por Scanlon, como é possível encontrar em Rawls uma tensão entre a garantia de igual direito de participação política a todos, de um lado, e a permissão de desigualdades socioeconômicas, de outro.

Palavras-chave: Justiça. Desigualdade. Participação.

\section{ECONOMIC INEQUALITY AND POLITICAL RIGHTS IN RAWLS' THEORY OF JUSTICE: AN ANALYSIS FROM THOMAS SCANLON}

\section{ABSTRACT}

The present article, of bibliographical nature, intends to problematize the way the issue of how socioeconomic inequalities and political rights are dealt with in the theory of justice originally formulated by John Rawls. It is well known that Rawls, in the decade of 1970, performed a revolution in the debates about distributive justice with the formulation of the theory that became known as justice as fairness, which is based in the proposition of two principles of justice, the first having priority over the second, in order to rule society's basic structure. Very recently, however, a set of theoretical challenges to the liberal egalitarian tradition, to which Rawls is a major figure, was presented by Thomas Scanlon, in his proposal of attributing equality an intrinsic value. The work aims to show how one of the issues raised by Scanlon, concerning political participation, can be capable of seriously compromising Rawls's original proposal, in a way that the distribution prescribed by the principles themselves would break the priority between them. Firstly, we shall make a systematic study of how Rawls elaborates his two principles of justice and what is the place of equality within them, emphasizing the relevant elements to the subsequent analysis. Then, we shall try to demonstrate, starting from the point of view offered by Scanlon, how it is possible to find in Rawls a tension between the guarantee of a right to equal political participation to all, on the one hand, and the permission to socioeconomic inequalities, on the other.

Keywords: Justice. Inequality. Participation.

\section{SUMÁRIO}

1 Introdução. 2 A teoria da justiça de Rawls. 2.1 Os dois princípios de justiça. 3 A proposta de Scanlon. 3.1 Quebra da prioridade lexical. 4 Conclusão.5 Referências. 


\section{INTRODUÇÃO}

No campo da filosofia política e do Direito, uma das questões mais antigas, porém ainda sem solução definitiva, diz respeito à admissibilidade da desigualdade social. Mais especificamente, o problema gira em torno de determinar se é moralmente aceitável que dentro de uma sociedade diferentes indivíduos detenham porções desiguais dos recursos disponíveis, e, caso o seja, com base em que critério pode-se indicar quais são as desigualdades justificadas.

Na verdade, a questão das desigualdades, como problema jurídico e filosófico, insere-se em uma temática mais ampla, a saber, a determinação de qual é a maneira justa de distribuir os recursos produzidos e explorados pela sociedade. Contemporaneamente, a resposta mais importante dada a essa pergunta foi aquela formulada por John Rawls, em sua grande obra A Theory of Justice" (1971). Nesse livro Rawls propôs que a sociedade fosse vista como um sistema de cooperação entre os indivíduos, cuja estrutura básica seria regida por princípios gerados a partir de um experimento mental dotado de imparcialidade.

Nesta perspectiva, o objetivo deste texto, por meio de um estudo de caráter bibliográfico, é mostrar como uma das questões levantadas por Scanlon, concernente à questão da participação política, pode ser capaz de comprometer seriamente a proposta original de Rawls de tal forma que a distribuição indicada como justa pelos próprios princípios acabaria por quebrar a prioridade estabelecida entre eles. Primeiramente, faremos um estudo sistemático de como Rawls elabora seus dois princípios de justiça e qual o lugar da igualdade dentro deles, com ênfase para os elementos relevantes para a análise posterior. Em seguida, tentaremos demonstrar, a partir do ponto de vista oferecido por Scanlon, como é possível encontrar em Rawls uma tensão entre a garantia de igual direito de participação política a todos, de um lado, e a permissão de desigualdades socioeconômicas, de outro.

É amplamente sabido que a proposta de Rawls não foi pacificamente aceita à época. Pelo contrário, ela suscitou uma reanimação das discussões sobre justiça social e atraiu críticas de todos as perspectivas possíveis, desde aquelas vindas de seu próprio nicho ideológico (o liberalismo igualitário), até aquelas baseadas em sua concepção de indivíduo e de racionalidade

Assim, o espectro da Filosofia do Direito contemporânea após Rawls se reestruturou de tal forma que as discussões sobre a admissibilidade de desigualdades passaram a ser discussões, primordialmente, sobre por que é moralmente obrigatório (ou não) que uma sociedade seja igual no quesito socioeconômico. Em outras palavras, os debates quanto a essa questão majoritariamente são debates em que se argumenta sobre se é necessário que o valor da igualdade seja instaurado ou não.

Nunca antes, contudo, havia sido feita uma abordagem que procedesse da forma contrária. Isto é, nunca antes algum autor preocupou-se não em defender porque deve existir igualdade, mas sim quais são os motivos para se rejeitar a desigualdade. É exatamente essa proposta inovadora que pode ser encontrada no recente livro de Thomas Scanlon, que tem por título Why Does Inequality Matter? (2018). Scanlon pretende examinar seis tipos de desigualdades que podem existir entre os indivíduos - algumas das quais muitas vezes não abordadas nos debates mais frequentes sobre o tema - e apontar em cada uma qual a sua problemática moral. Trata-se de obra recentíssima e cujo teor é de grande relevância para discussões relativas à legitimidade das instituições sociais, sobretudo do Direito.

Em última instância, Scanlon tentará mostrar que as desigualdades por si mesmas são moralmente objetáveis, de sorte que a única opção política coerente seria aquela em que a igualdade é tratada como valor intrínseco. Neste artigo, tentaremos mostrar como um dos argumentos formulados por Scanlon, concernente à questão da desigualdade entre os indivíduos no poder de influência política que cada um possui, pode ser utilizada para problematizar a resposta de Rawls sobre os critérios de aceitabilidade das desigualdades sociais.

Rawls havia proposto que toda e qualquer desigualdade, para ser admissível, precisa, antes de tudo, não interferir na igualdade entre os indivíduos quanto aos direitos e liberdades básicas. O texto pretende sustentar que, com base na argumentação de Scanlon, como algumas das desigualdades, a princípio aceitáveis para Rawls, acabariam por produzir a mesma iniquidade política que ele pretendera afastar. Assim, por meio de um exame bibliográfico, e com o emprego do método dedutivo, a argumentação a ser desenvolvida segue os seguintes passos. 
Em primeiro lugar, será feita uma exposição da teoria da justiça como a equidade tal como originalmente elaborada por Rawls, ao longo da qual tenta-se explicitar exatamente como a questão da desigualdade socioeconômica é tratada e como é traçada a relação entre direitos políticos e a prioridade lexical do primeiro princípio sobre o segundo. Após isso, procede-se a uma análise do argumento de Scanlon sobre como disparidades socioeconômicas entre os indivíduos têm como consequência praticamente inevitável a produção de disparidades correspondentes da capacidade que cada um possui de influenciar o processo de tomadas de decisão dentro das instituições sociais.

Por último, busca-se conectar essas duas partes em uma argumentação sobre como a abordagem de Scanlon abre caminho para uma crítica direta a Rawls. Mais especificamente, defende-se que a prioridade lexical entre os dois princípios de justiça, tal como elaborada pelo filósofo estadunidense, permitiria a existência de desigualdades entres os indivíduos que, no longo prazo, tenderiam a corroer a distribuição perfeitamente igualitária de direitos políticos estabelecida pelo primeiro princípio.

\section{A TEORIA DA JUSTIÇA DE RAWLS}

Está para além de qualquer dúvida que a teoria da justiça formulada por John Rawls foi a mais criativa e inovadora abordagem sobre justiça distributiva surgida no século 20. Em relação a todas as outras concepções de justiça que a antecederam, sejam as antigas, medievais ou modernas, a teoria de Rawls possui um diferencial que a torna única. Trata-se do fato de que ela não pretende apenas ser convincente em suas teses ou coerente quanto as suas premissas. De fato, nela podemos encontrar preocupações de dois tipos distintos: uma de ordem teórica e a outra de ordem política.

Com efeito, a própria estrutura da escrita do autor em seu primeiro grande livro, Uma Teoria da Justiça (1971), deixa bastante evidente a presença de uma preocupação em estabelecer de forma clara os pressupostos a serem considerados e definir inequivocamente o escopo das afirmações ali feitas. É importante lembrar que isso precisa ser levado em consideração não apenas para a análise que pretendemos aqui desenvolver, mas também por qualquer um que pretenda criticar ou endossar o pensamento rawlsiano. Existe ainda, entretanto, uma outra preocupação até então inédita, a saber, a preocupação de que a teoria poderia ser racionalmente aceita do ponto de vista de todos os envolvidos.

Segundo Catherine Audard (2007), importante estudiosa da obra de Rawls, a teoria da justiça como equidade carrega consigo elementos oriundos tanto de seu contexto político como de seu contexto filosófico. Historicamente falando, a proposta de Rawls é forjada no período em que o mundo se encaminha para o ápice da polarização global entre o bloco capitalista e o bloco socialista, momento este em que, exatamente em razão da disputa entre esses dois modos de produção, os temas da propriedade privada, da acumulação do capital e distribuição de renda despontam como cerne das discussões na esfera pública.

Deve-se lembrar, ainda a título de contextualização temporal, que também na década de 70 do século 20, o mundo havia assistido à ascensão de movimentos sociais reivindicando tanto reparações para grupos historicamente oprimidos (mulheres, negros, etc.), quanto questionamentos das formas de vida vigentes (movimento hippie), quanto oposição a atitudes institucionais (movimento contra a Guerra do Vietnã). Tais eventos reverberaram na filosofia política na medida em que suscitaram novos problemas, por exemplo: Quais os limites de atuação legítimos das instituições? Que regime de direitos e deveres deve ser atribuído a cada cidadão? Qual o papel do Estado dentro da economia? E, finalmente, qual é a maneira justa de se distribuir recursos e oportunidades entre as pessoas?

Já no que se refere a correntes filosóficas, a teoria de Rawls (1971) pretende servir como alternativa viável às duas outras formas de se pensar a justiça distributiva que até então possuíam maior proeminência, porém enfrentavam um momento de certa estagnação e esgotamento. Trata-se do utilitarismo, de um lado, e do intuicionismo, de outro.

Hegemônico no mundo anglo-saxão, pelo menos desde a segunda metade do século 19, o utilitarismo apresentou-se como uma teoria capaz de distinguir o moral do imoral, o justo do injusto, por meio de um critério pretensamente palpável e mensurável, a saber, o bem-estar humano. Inicialmente foi formulado como parte de um projeto político reformador de larga escala, cuja pretensão principal era apontar como as instituições que regem a sociedade, notadamente o ordenamento jurídico, deveriam ser modificadas de maneira a se tornarem mais racionais, menos dependentes da tradição e da superstição e menos comprometidas com 
os interesses de específicos grupos sociais aristocráticos. De caráter teleológico, a tese central do utilitarismo moderno quanto à justiça comum e todas as suas acepções é de que é justa aquela medida institucional que produz o maior bem-estar para o maior número de indivíduos (MULGAN, 2012).

Em contrapartida, o intuicionismo advoga exatamente a noção contrária. Em vez de também formular um critério para dizer o que se pode considerar como justo, o intuicionismo simplesmente adota a posição de que nossos juízos sobre a justiça são pautados em intuições que todos possuem. Essas intuições são várias e diferenciadas entre si. Dentro de situações concretas, o que acontece é que essas mesmas intuições podem conflitar entre si. Quando isso ocorre, uma delas terá precedência e prevalecerá sobre a outra. Para o intuicionismo, contudo, não há, em última instância, nenhum parâmetro com o qual seja possível determinar qual será a intuição prevalente, de tal sorte que não há que se falar em uma regra definitiva e geral sobre o que conta como justo ou injusto.

Com estas observações contextuais, temos reunidos vários dos pontos relevantes para nossos propósitos neste artigo. Já sabemos, pelas circunstâncias históricas, que a teoria de Rawls tem como centro de suas atenções a questão da definição do rol de direitos e deveres que assistem a cada indivíduo e a possibilidade de distribuição desigual de recursos econômicos. E pelas circunstâncias filosóficas, sabemos que a forma como o autor deseja responder a esses problemas é tal que não recaia nem, primeiro, na redução da justiça aos critérios da moral na esfera individual (como o utilitarismo), nem, segundo, em uma situação em que falte um critério objetivo e preciso (como o intuicionismo).

Em outras palavras, a tarefa que Rawls toma para si consiste em harmonizar a busca de cada um pelo seu próprio projeto de vida com uma concepção de justiça que não se confunde com qualquer desses projetos de vida. Não apenas isso, porém. Tem de ser, ainda, uma concepção que encontra uma forma de comportar aquelas intuições cotidianas que nos parece inaceitável violar, no entanto não se resume a uma mera justaposição entre elas. É exatamente dessa dupla necessidade teórica - de frear as concepções de bem pessoais e de não se perder na pluralidade das intuições existentes - que surge a questão da prioridade lexical que queremos abordar (RAWLS, 1971).

Esse ponto é fulcral para que se possa compreender adequadamente por que Rawls simplesmente não coloca seus dois princípios de justiça como verdades evidentes ou derivadas da razão. Em vez disso, sua proposta trata-se de uma tentativa de apresentar princípios que poderiam ter sido eles próprios escolhidos pelos indivíduos de cuja sociedade irão reger. Como, no entanto, aquilo que cada um considera justo ou injusto é afetado por seus próprios interesses e sua posição social atual, a única forma de determinar qual é a distribuição justa de recursos é aquela em que o critério de distribuição não seja informado por qualquer uma dessas contingências.

O procedimento concebido para levar a cabo tal projeto é a famosa posição original. Trata-se de uma situação fictícia em que os indivíduos se encontram em posição de equidade em relação uns aos outros. Isso porque todos estão sob o chamado véu da ignorância, uma circunstância na qual ninguém sabe nada a respeito de sua própria identidade ou sobre as condições da sociedade em que vivem. Ninguém sabe qual sua idade, profissão, religião, metas pessoais ou patrimônio, assim como também desconhecem o local onde moram, o clima, as características geográficas e os recursos naturais de sua região. Assim colocados, os indivíduos terão à sua disposição uma lista de princípios de justiça possíveis, dos quais deverão escolher de forma unânime aquele que irá reger sua sociedade (RAWLS, 1971).

A ideia por trás da posição original é que, se nenhum dos participantes possui qualquer informação específica sobre si mesmo ou sobre seus interesses, então é impossível que qualquer escolha assim feita favoreça uns em detrimento de outros. Como todos possuem o mesmo nível de desinformação a respeito de si e de seu contexto social, qualquer escolha que traga um benefício para alguém estará potencialmente beneficiando todos ao mesmo tempo. Em outras palavras, a posição original é projetada de tal maneira que os princípios de justiça dela derivados serão seguramente imparciais e dispensarão a todos o mesmo tratamento.

Como observa Samuel Freeman (1996), há algo de kantiano na posição original. Ao conceber os indivíduos como desconhecedores de suas próprias concepções de bem e aspirações, Rawls produz um contrato imaginário no qual estão representados apenas aqueles traços que os definem enquanto agentes morais, a saber, sua racionalidade, sua capacidade de obedecer a uma concepção justiça, etc. É possível interpretar, 


\section{Debate}

nesse sentido, que, assim como Kant (2007) concebera que a moralidade só surge com o afastamento das inclinações, Rawls teria dito que os princípios de justiça só podem ser alcançados quando as contingências econômicas históricas e culturais são postas de lado.

Destarte, toda a justiça como equidade pode ser lida como a defesa de uma ideia fundamental: a ideia de que o destino de um indivíduo dentro da sociedade não pode ser determinado por outra coisa senão suas próprias escolhas. Equidade, nesse sentido, significa aquele estado de coisas em que as pessoas, por mais distintas que sejam suas origens, não tenham menos ou mais chances do que outras de realizar suas próprias concepções de bem. Politicamente, o que Rawls tem em vista é uma concepção de justiça que controle o modo como as principais instituições atribuem encargos e benefícios (a assim chamada estrutura básica da sociedade), ${ }^{1}$ a fim de que a influência das contingências da realidade social sejam minimizadas.

\subsection{Os dois princípios de justiça}

Dadas essas informações, podemos passar para uma análise sucinta do conteúdo dos dois princípios de justiça. Entre todas as opções disponíveis - incluindo o princípio de utilidade em sua forma original, o princípio de utilidade com modificações, o princípio de perfeccionismo moral, etc.- Rawls considera que os indivíduos na posição original acabariam por escolher seus dois princípios de justiça. Aquilo que os dois princípios se encarregam de distribuir são o que Rawls denomina de bens primários, ${ }^{2}$ as coisas as quais seria razoável presumir que todos os indivíduos desejam para si, por serem necessárias para a realização de qualquer concepção de bem.

O primeiro princípio trata da distribuição de direitos e liberdades, ao passo que o segundo ocupa-se da distribuição de bens econômicos (riqueza, renda, patrimônio, etc.). Analisemo-los por ordem. Todos os dois princípios são colocados por Rawls primeiro em uma forma preliminar e passam por sucessivas mudanças até atingir uma formulação acabada. No caso do primeiro princípio essa formulação pode ser encontrada em:

Cada pessoa terá igual direito ao mais amplo esquema total de iguais liberdades básicas compatível com um sistema de liberdade semelhante para todos.

Regra de prioridade

Os princípios de justiça serão elencados em ordem lexical, de forma que a liberdade possa ser restringida apenas em prol da própria liberdade. Há dois casos: (a) uma liberdade menos extensa deve fortalecer o sistema total de liberdades compartilhado por todos, e (b) uma liberdade desigual deve ser aceitável para todos aqueles com liberdade reduzida (RAWLS, 1971, p. 250, tradução livre).

O texto por si só já é bastante didático. O que o primeiro princípio de justiça nos revela é que não é aceitável que uma pessoa tenha uma carga menor de direitos e liberdades básicas do que outra, a menos que isso seja plenamente justificado dentro de certas hipóteses predeterminadas. Liberdades básicas é a expressão que Rawls usa para se referir a um conjunto de liberdades que não é exaustivamente delimitado - ou seja, liberdades que não podem formar um rol fechado e finito, uma vez que mudanças nas circunstâncias sociais podem gerar a necessidade de se proteger juridicamente liberdades que antes não o eram - mas cujos exemplos dados pelo próprio Rawls permitem inferir que dizem respeito àquelas liberdades que desde o começo da modernidade estiveram no centro das pautas liberais. Liberdade de expressão, liberdade de pensamento, liberdade de locomoção, a possibilidade de ser titular de propriedade, entre outras.

Desse modo, o primeiro princípio expressa, com uma linguagem mais sofisticada e alguns novos detalhes, a máxima típica de teorias liberais, segundo a qual todos são iguais em direitos e deveres. O motivo mais direto pelo qual um princípio como este seria escolhido na posição original é que não seria razoável que

\footnotetext{
Há certa indeterminação em Uma Teoria da Justiça sobre exatamente quais instituições fazem parte da estrutura básica da sociedade. O que se pode ter certeza é que o Estado e o mercado o são, mas há certa dúvida, por exemplo, sobre se a família como instituição também seria. Inclusive, a questão da relação entre família e justiça social é um dos aspectos-chave para o debate entre a teoria rawlsiana e o feminismo em suas diversas versões. A esse respeito, é interessante a exposição de Roberto Gargarella (2008).

2 É interessante observar que o conceito de bens primários é anterior à teoria madura de Rawls, remontando ao período em que ele ainda a apresentava em versões fragmentadas à comunidade acadêmica na década de 60. Já naquele período Rawls (mais especificamente, em um artigo de 1968) considerava que os bens primários são: direitos, liberdades, renda, riqueza, oportunidades e o autorrespeito, este último dotado de uma complexidade especial que não pode ser analisada aqui.
} 
as partes do contrato acordassem uma disposição diferente. Nenhum indivíduo dotado de plena consciência e um mínimo de raciocínio prospectivo concordaria com uma distribuição desigual de direitos e liberdades previamente estabelecida, pois sempre haveria a possibilidade de que este indivíduo, dentro da sociedade operante, fosse um daqueles com uma parcela de direitos reduzida.

O primeiro princípio, no entanto, também possui um significado político mais sutil que não pode ser descartado: a atribuição de um igual e mais amplo esquema de liberdades básicas que cumpra a função de produzir em cada um senso igual de cidadania. Quer dizer, o caráter igualitário da distribuição de direitos e liberdades serve ao propósito de fazer com que os membros da sociedade se reconheçam como detentores do mesmo valor na condição de cidadãos. Trata-se de fazer uma equiparação entre as pessoas, de sorte que, mesmo quando elas sejam desiguais economicamente, ainda sejam plenamente iguais como sujeitos de direito.

Por essa razão, toda e qualquer organização de caráter estamental ou em castas resta excluída pelo primeiro princípio. $O$ conjunto das liberdades básicas também constituem as condições necessárias para que cada um formule e persiga sua própria concepção de bem. O esquema tem de ser "o mais amplo" a fim de que ao indivíduo seja assegurado um certo rol de escolhas que somente ele pode fazer por si e jamais qualquer outra pessoa em seu lugar, nem mesmo quando todos os demais poderiam se beneficiar da restrição de sua liberdade. ${ }^{3}$

Disso se pode extrair uma informação relevante. A maneira como Rawls concebe direitos e liberdades é estritamente negativa. Significa dizer que direitos e liberdades, na teoria rawlsiana, são pensados apenas como limites que outros não podem ultrapassar, não mais do que proteções contra a interferência de terceiros. Tal concepção é um equivalente quase exato daquilo que Constant (2019) caracteriza como "liberdade dos modernos".

Nesse sentido, Thomas Pogge (2007) ressalta que a noção rawlsiana de direitos e de liberdade possui apenas duas dimensões: a extensão (extent) e a proteção (security). A extensão diz respeito ao escopo do direito/liberdade em questão, isto é, refere-se àquilo que eles permitem ao indivíduo fazer. A proteção, por sua vez, tem a ver com as medidas adotadas pelas instituições para efetivamente evitar que o exercício do direito/ liberdade seja afetado por coerção ou violência indevida.

Não há, na concepção de direitos e liberdades de Rawls, uma preocupação material sobre se o indivíduo dispõe ou não dos meios e das condições necessárias, e sim uma preocupação formal sobre se o direito é reconhecido pelas instituições e se elas tomam providências contra interferências indevidas. Quando uma pessoa tem menos habilidade ou menos condições do que outra de exercer certa liberdade, para Rawls, não significa que ela tenha liberdades diferentes, mas sim que as suas liberdades têm um valor diferente, o que por si só não é algo inadmissível. Rawls afirma várias vezes que é preciso especialmente que as liberdades relacionadas à política tenham valor igual ou equitativo para todos, aspecto que exploraremos logo adiante (SCANLON, 1973).

Por sua vez, o segundo princípio, como já referimos, é o responsável por regular a distribuição de bens econômicos. É com base nele que se determina como os indivíduos podem atingir diferentes posições de liderança e chefia dentro da sociedade e quais desigualdades podem existir. É, pois, um princípio voltado ao mercado como instituição componente da estrutura básica da sociedade, impondo-lhe os freios necessários para que o estado de coisas resultante seja sempre justo. A formulação completa deste princípio é dada por Rawls da seguinte forma:

Desigualdades sociais e econômicas devem ser configuras de tal forma que sejam tanto:

a. Para o maior benefício dos menos favorecidos, consistentemente com o princípio das economias justas e

b. Vinculadas a cargos e posições abertos a todos em condições de igualdade equitativa de oportunidades (1971, p. 302, tradução livre).

\footnotetext{
A concepção dos direitos individuais como as fronteiras últimas que nem a sociedade civil inteira nem o Estado podem ultrapassar não é específica de Rawls. Na verdade, pode ser encontrada de uma forma ou de outra em praticamente todos os autores liberais, tendo um de seus desenvolvimentos mais importante em Dworkin, com sua famosa concepção de direitos como trunfos.
} 
Novamente, a redação de Rawls é de notável clareza. Em linhas gerais, o que o segundo princípio pretende estabelecer é que não podem existir quaisquer desigualdades sociais. Afastando-se de concepções de justiça socialistas, Rawls admite que a sociedade justa possa ter disparidades econômicas entre seus membros, mas essas disparidades só serão aceitáveis se atenderem àquele par de critérios supracitado, mas de forma alguma é possível se confundir com utilitarismo, uma vez que a permissibilidade dessas desigualdades em absoluto tem a ver com a produção de simples bem-estar para a maioria.

Em vez disso, Rawls elabora um critério de complexidade consideravelmente maior. Mais precisamente, são duas as partes que compõem o segundo princípio, uma tendo novamente prioridade sobre a outra, na seguinte ordem.

O primeiro subprincípio estabelece que só poderá haver uma desigualdade socioeconômica se ela deriva de cargos e posições abertos a todo em igualdade equitativa de oportunidades. Aqui há tanto uma dimensão formal quanto uma dimensão material. A dimensão formal é que ninguém pode ser impedido de disputar ou concorrer a um desses cargos. Exclui-se, assim, qualquer hipótese de privilégio econômico em razão do nascimento ou da origem. A dimensão material é que todos os interessados em atingir um mesmo cargo ou posição precisam dispor das mesmas condições de preparação para tal, sem que um seja colocado em desvantagem desde o começo por possuir menos recursos que o outro.

O segundo subprincípio, famoso como princípio da diferença, coloca ainda um outro filtro para as desigualdades. Não basta que elas derivem de cargos acessíveis com oportunidades equitativas. É preciso, além disso, que a existência dessa desigualdade coloque os menos favorecidos na melhor situação possível. Em outros termos, uma desigualdade socioeconômica, para ser aceitável, deve beneficiar não apenas aqueles que forem diretamente favorecidos por ela; devem, também, gerar resultados positivos para os que não são por ela contemplados.

Na prática, o princípio da diferença de Rawls quer expor que as desigualdades jamais podem ser aleatórias. Antes, elas precisam servir a algum papel dentro da sociedade. Uma profissão ou uma certa carreira só poderia receber remuneração melhor do que outras se esta remuneração diferenciada de alguma forma beneficia inclusive os que não fazem parte dela.

Rawls acredita que a escolha desses dois subprincípios para, juntos, compor o segundo princípio de justiça, também se fundamente no tipo de raciocínio autointeressado que as partes na posição original teriam. Se, uma vez assegurados plenamente seus direitos, os indivíduos notarem que certas desigualdades são capazes de melhorar suas circunstâncias individuais, não haveria razão para não admiti-las. Pressupondo que nenhum deles se incomoda com as condições do outro desde que a sua não seja afetada, o mais racional seria que todos concordassem em permitir aquelas desigualdades que trouxessem algum benefício para todos individualmente.

Obviamente, nenhum indivíduo plenamente racional aceitaria ser sumariamente excluído da possibilidade de gozar daquelas posições privilegiadas. Por isso todos acordariam que essas desigualdades precisariam ser tais que todas as pessoas pudessem almejar alcançá-las, ou seja, abertas à livre concorrência entre os indivíduos. Tampouco admitiriam que meras contingências, como nascer pobre, pudessem afetar as chances nessa competição, do que se deriva a exigência de igualdade equitativa de oportunidades.

E de que forma poderia uma desigualdade ser benéfica para todos? A resposta de Rawls (1971) a essa questão tem a ver com o fato de que recompensas diferenciadas poderiam funcionar como incentivos. Aqueles cargos, ofícios e profissões mais difíceis, exigentes e custosos em termos de preparação e treinamento precisariam ser mais bem recompensados para que os indivíduos pudessem sentir-se estimulados a participar deles. Ademais, quanto mais indivíduos envolvidos nessas posições, mais resultados positivos seriam gerados para a sociedade como um todo.

Assim, no entender de Rawls, se o mercado remunera melhor o médico do que o faxineiro, isso funcionaria como um atrativo para que mais indivíduos decidissem enveredar pela carreira médica. Isso, por sua vez, tende a elevar o nível dos serviços de saúde disponíveis na sociedade, o que favorece os interesses inclusive dos indivíduos que não são médicos. Provavelmente, a maior inovação que se pode encontrar aqui é a defesa de que a desigualdade não pode simplesmente ser permitida; ela precisa impreterivelmente servir às pessoas (FREEMAN, 2007). 
Com efeito, pode-se perceber um certo ideal ético presente nessa proposta, que torna bastante explícito o caráter deontológico da teoria de Rawls. Não importa o quão grandiosos sejam os resultados que poderiam ser obtidos pelo afrouxamento das rédeas do mercado, é preciso abrir mão deles se não se conformarem aos requisitos do segundo princípio. Dito de outro modo: no que respeita à distribuição de renda e riqueza, a eficiência sempre deve se curvar à justiça, que prevalece como valor supremo no funcionamento das instituições.

\section{A PROPOSTA DE SCANLON}

Feitas essas colocações, nosso primeiro objetivo foi alcançado. Ao estabelecermos a dimensão político-moral de cada um dos princípios de Rawls, podemos perceber de que maneira o valor da igualdade se faz presente. A justiça, em Rawls, não tem a ver com criar um estado de coisas em que os indivíduos possuem um mesmo nível de recursos; mas sim, como havíamos mencionado, com criar um estado de coisas em que o seu grau de sucesso ao perseguir uma concepção de bem não seja determinado por fatores contingentes e alheios à sua vontade.

Então, um dos sentidos da distribuição rawlsiana é fazer uma alocação de recursos que, do ponto de vista de indivíduos com posições distintas dentro da sociedade, seja recíproca. Um recebe um benefício (como um salário maior), e outro recebe um outro benefício correlacionado (como a possibilidade de dispor de um serviço importante). Tudo isso, é importante lembrar, sem que a igualdade plena no plano dos direitos e liberdades seja afetada, conforme estabelece a prioridade lexical entre o primeiro e o segundo princípio. Não é possível admitir qualquer desigualdade se ela tem como efeito diferençar as pessoas também quanto aos direitos e liberdades de cada uma.

Esta ideia, da admissibilidade das desigualdades estar condicionada às iguais liberdades permanecerem intactas, já foi alvo de críticas em mais de uma ocasião. Entre elas, certamente merece destaque a crítica dirigida pelo ex-professor de Rawls, H. L. A. Hart (1973), com base no argumento de que escolha por essa regra de prioridade só faria sentido para alguém que já adotasse um liberalismo deontológico. Seguindo esse raciocínio, a teoria da justiça como equidade estaria comprometida com uma certa ideologia política desde o começo, prejudicando assim sua pretensa capacidade de imparcialidade.

A hipótese que queremos apresentar, contudo, é de que também é possível encontrar uma outra tensão entre os dois princípios de Rawls e a relação de prioridade entre eles quando a justiça como equidade é olhada pelo prisma das questões recentemente levantadas por Thomas Scanlon.

Scanlon é um autor já antigo no debate sobre teorias da justiça. Desde a década de 70 esteve entre aqueles que fizeram as primeiras análises e tentativas de exegese da teoria da justiça de Rawls. Suas próprias contribuições para o campo da filosofia política normalmente tendem a levar a comunidade acadêmica a classificá-lo também como um liberal igualitário (como Rawls, Dworkin e Sen) e com estratégia argumentativa neocontratualista (como Rawls e Gauthier), com nuances em relação a outros autores das mesmas linhas.

Apesar de toda a produção considerável de Scanlon ao longo de sua carreira, nossa atenção centrar-se-á em sua última obra publicada, que tem como título Why Does Inequality Matter? (2018). Antes de fazer qualquer consideração sobre os argumentos que nele se encontram, é importante ter em mente qual é sua proposta. Scanlon está ciente de que muitas das discussões sobre justiça distributiva giravam em torno da questão da igualdade, de seu valor, da necessidade de sua realização, etc. Com seu mais recente livro, Scanlon pretende reconfigurar o foco da investigação. Em vez de questionar por que deva haver igualdade, sua proposta é interrogar o que há de errado na desigualdade.

As questões parecem ser iguais, mas essa é uma identidade apenas aparente. Se perguntar pela igualdade equivale a investigar por que não deva haver diferenças, perguntar pela desigualdade equivale a analisar o que está incorreto quando as diferenças estão presentes. Scanlon então procederá a uma análise detida sobre seis formas diferentes de como pode haver desigualdade entre os indivíduos e assim expor quais são as razões morais pelas quais cada uma dessas desigualdades são objetáveis. Nas palavras do autor:

Precisamos de uma abordagem clara sobre as razões para nos importarmos com igualdade e desigualdade. Também necessitamos de uma tal abordagem para compreender o que há de errado com leis e instituições que promovem desigualdade, e como mudanças nessas instituições a fim de produzir igualdade social podem 
ser justificadas. Mesmo que fosse algo bom que os pobres estivessem em melhores condições, ou se fosse bom que as diferenças entre pobres e ricos diminuíssem, ainda poderia ser que a consecução desses objetivos por meio da redistribuição fosse algo errado (SCANLON, 2018, p. 3, tradução livre).

Claramente não é possível aqui fazer alusão aos argumentos de Scanlon para os vários tipos de desigualdade que são estudadas em seu livro. Nessa perspectiva, é importante deixar claro, a abordagem de Scanlon se distingue da de Rawls porque, diferentemente deste último, o autor tem como pretensão elaborar uma teoria da justiça unificada que forneça critérios capazes de solucionar todas as questões de justiça distributiva no âmbito das instituições sociais. Em vez disso, como mencionado anteriormente, trata-se muito mais de fazer um levantamento de quais são os principais contextos da vida social em que a desigualdade socioeconômica se faz presente de forma saliente para então demonstrar por qual ela seria moralmente objetável segundo as especificidades daquela situação em particular.

A pluralidade temática e a diversidade de ângulos de análise encontradas na obra de Scanlon tornam seu estilo de fazer filosofia política sensivelmente diferente do de Rawls. Se este tinha a pretensão de deduzir quais os critérios para a distribuição de benefícios e encargos que poderia ser aceita em uma posição hipotética de equidade, aquele está muito mais preocupado em saber quais são as repercussões concretas da existência da desigualdade nas mais diversas esferas da vida social, elucidando como elas se combinam para produzir situações de desvantagens comparativas cada vez maiores entre os indivíduos.

Essa diferença metodológica entre os dois autores, um de orientação mais normativa e abstrata e o outro de orientação mais prática e concreta, é um elemento que torna a análise de um à luz do outro ainda mais interessante. Assim, a abordagem de Scanlon proporciona as informações empíricas necessárias com as quais seria possível avaliar até que ponto a proposta de Rawls é capaz de produzir o estado de coisas que ele considera como ideal.

Destarte, no bojo de suas análises, Scanlon (2018) será levado a se debruçar sobre uma diversidade de questões de justiça ao longo de sua obra. A distribuição desigual dos benefícios gerados por políticas públicas, a questão do mérito e do esforço pessoal no mercado de trabalho, assim como os critérios de seleção para cargos oficiais remunerados são algumas das problemáticas abordadas no livro. Embora todas essas discussões concentrem-se no mesmo aspecto, a saber, a desigualdade socioeconômica, cada uma delas incorpora premissas próprias, fazendo com que delas resultem argumentos que possuem certo grau de autonomia.

Exatamente em virtude desse caráter eclético e variado do pensamento de Scanlon, é mais adequado, metodologicamente falando, selecionar apenas o argumento mais pertinente para a temática tratada neste artigo. Para nossos fins, o que importa de fato é aquilo que o autor tem a dizer sobre a questão da equidade no campo da política, ou seja, no exercício dos direitos políticos, de votar e de ser votado. Até mesmo este argumento, que pode ser encontrado em sua melhor versão no capítulo 6ㅇ da obra, possui certa complexidade por si mesmo, o que nos obriga a selecionar apenas algumas de suas premissas e etapas para tornar mais precisa nossa discussão.

Em primeiro lugar, Scanlon quer deixar clara a distinção entre analisar a igualdade dentro da política e analisar a igualdade dentro de outros postos ou cargos dentro da sociedade. Instituições de natureza não diretamente política e não eletiva, como universidades, bancos, hospitais, entre outros, possuem uma forma de justificação estruturalmente diferente daquela que é válida para instituições políticas.

Instituições como essas primeiras se justificam na medida em que tenham algum papel a desempenhar ou alguma utilidade (não no sentido do utilitarismo) para oferecer. Precisam servir a algum propósito relevante. Mais do que isso, os indivíduos selecionados para operar essas instituições precisam ser tais que a sua presença nelas de fato concretize o propósito para o qual foram criadas.

Nesse viés, a seleção de um indivíduo para ocupar um lugar em uma instituição como essa (para ocupar uma vaga de emprego, por exemplo) é justificada apenas quando os critérios dessa seleção são exatamente aquelas qualidades necessárias que alguém precisaria ter para conferir funcionalidade àquela posição e, consequentemente, àquela instituição. Aqui, a relação com a igualdade equitativa de oportunidades rawlsiana é clara: toda seleção dessa espécie é injustificada quando os indivíduos possuem oportunidades diferentes para se prepararem para ocupar aquela posição. 
Já nas instituições de natureza política e preenchidas pela via eleitoral, temos uma configuração com diferenças importantes. Para cargos eletivos, o que importa também é que a pessoa ocupante tenha sido preferida e desejada para estar lá pelos membros da comunidade, do contrário não se pode falar que há representação genuína de ninguém por parte de ninguém.

Por outro lado, Scanlon (2018) observa que um governo também é atacável quando as escolhas dos governantes atendem apenas aos interesses daqueles que o elegeram. Isso porque todas as ações governamentais afetam diretamente a capacidade dos indivíduos de realizarem sua própria concepção de bem, entre as quais uma não pode ser reputada como mais valiosa que outra. Se o governo age de tal forma a beneficiar apenas os que estão a seu favor, ele lhes dispensa uma consideração desigual, o que é moralmente inaceitável.

Scanlon reúne essas premissas, que se acumulam de suas análises anteriores, com alguns dados obtidos por pesquisas empíricas a respeito da influência que as desigualdades econômicas podem exercer sobre questões políticas, como votação de projetos de lei, processos de licitação, etc. Em linhas gerais, o que essas pesquisas apontam é que a distribuição desigual de renda e riqueza dentro da sociedade faz com que os mais ricos tenham maiores possibilidades de ver seus interesses atendidos pelos governantes do que os mais pobres.

Por qual razão, todavia, exatamente isso seria moralmente objetável? Para Scanlon (2018), o problema moral com a disparidade econômica se alastrar para a política está no fato de que entre ricos e pobres há desacordos tão importantes a ponto de afetar a vida de grupos inteiros dentro da sociedade. Em praticamente todas as questões que envolvem alocação de recursos - como impostos, programas sociais, serviços públicos - é altamente provável, para não dizer inevitável, que as opiniões entre mais abastados e menos favorecidos divirjam completamente.

Ora, continua Scanlon, se nesse cenário for verdade que o grupo dos ricos possui mais poder para levar a cabo suas pretensões em detrimento dos pobres, então estamos falando de uma situação em que alguns (os mais pobres) perdem boa parte de sua possibilidade de fazer as instituições políticas agirem em seu favor. Perdem, portanto, parte de sua capacidade de controlar seus próprio bem-estar e seu próprio destino.

Assim, o caráter moralmente objetável da desigualdade na política gerada pela desigualdade econômica de fundo deve-se ao fato de que esta última desigualdade confere aos mais ricos um poder de controle sobre a esfera pública que lhes permite manuseá-la de uma forma que os mais pobres não podem. Scanlon admite que esse seja um fato de caráter contingente. É possível conceber um mundo em que haja pessoas pobres e ricas sem que estas usem o poder derivado de sua riqueza para conduzir a política em rumos desfavoráveis a aquelas. O próprio autor, contudo, também observa que todas as evidências a respeito da realidade mostram o quão implausível é acreditar que possa haver um mundo assim. Na verdade, é praticamente impossível desvencilhar uma coisa da outra (SCANLON, 2018).

Não bastasse isso, Scanlon chama a atenção também para a maneira como a desigualdade socioeconômica pode afetar inclusive o pano de fundo no qual se dão as tomadas de decisão no campo político. Para que qualquer pessoa seja capaz de formular um juízo sobre qual candidato ou partido mais corresponde às suas preferências, é preciso, no mínimo, que ela esteja bem informada sobre a situação atual da sociedade e das implicações de cada tipo de plano político, critério este que não pode ser igualmente atingido por todas as pessoas se elas não gozarem das mesmas possibilidades de acesso a uma formação educacional de qualidade.

De outro lado, é impossível que qualquer um seja bem-sucedido na competição por um posto no âmbito da política se não tiver condições de fazer com que suas propostas e sua perspectiva sejam conhecidas por todos os demais e amplamente difundidas entre os cidadãos. Na realidade, isso se traduz, por exemplo, na questão do financiamento eleitoral. Quem dispuser de menos recursos para esse fim inevitavelmente terá chances menores perante os concorrentes que possuem mais. Novamente, a questão da distribuição de renda e riqueza não esconde sua extensão para a política.

\subsection{Quebra da prioridade lexical}

Os passos aduzidos anteriormente levarão Scanlon à conclusão de que o valor equitativo das liberdades políticas de que falava Rawls precisa ser entendido por uma perspectiva diferente da interpretação usual. Normalmente, compreende-se que Rawls teria querido dizer que todos os indivíduos devem ser politicamente capazes das mesmas coisas, ou seja, que todos deveriam possuir as possibilidades de influenciar os rumos da 
política a seu favor. Para que a questão das liberdades na política, no entanto, possa ser compatibilizada com as outras problemáticas levantas por Scanlon, é preciso atribuir um novo sentido, como podemos ver nos termos do próprio autor:

\begin{abstract}
Se os ricos tivessem maior probabilidade de sucesso nesses quesitos porque a maioria dos votantes particularmente admira pessoas ricas e confia em seus julgamentos, isso não indicaria uma ausência de equidade das instituições políticas, o que quer que isso possa nos dizer sobre a sabedoria do eleitorado. Uma falta de equidade haveria, no entanto, se os ricos tivessem maior probabilidade de obter cargos e influenciar políticas porque sua riqueza maior os tornam muito mais capazes de concorrer a cargos e participar da política de outras formas, como apoiando outras campanhas políticas.

Concluo a partir disso que o ponto de Cohen sobre a igual oportunidade de influência política deveria ser entendido como igual acesso aos meios para atingir cargos e, de forma mais geral, influenciar a política pelo processo eleitoral (SCANLON, 2018, p. 80, tradução livre).
\end{abstract}

Scanlon, então, concordando com Joshua Cohen, enfatiza que a verdadeira igualdade no campo da influência política só pode existir se todas as pessoas possuírem os mesmos meios para exercer sua influência, os mesmos recursos que permitem que essa influência seja praticada. O que é curioso a respeito dessa conclusão é que havia partido da ideia de igual valor das liberdades políticas de Rawls, mas veio a assumir uma conotação quase que totalmente diferente daquela que Rawls dá a essa ideia.

Destarte, como mencionamos anteriormente, Rawls é bastante claro ao explicar que o seu igual esquema de liberdades básicas não significa que todas as pessoas ao mesmo tempo precisam ter tudo aquilo que é preciso para exercer plenamente essas liberdades. Um indivíduo continua sendo livre para ir e vir mesmo que suas atuais circunstâncias o privem dos recursos necessários para que ele pudesse se deslocar até determinado local de sua preferência. Isso decorre, vale enfatizar, do caráter negativo que o conceito rawlsiano de direito e de liberdade possui. A exceção mais importante enfatizada por Rawls, vale repetir, é a das liberdades políticas.

Se é verdadeira, o entanto, a conclusão de Scanlon, e não há outra forma de entender coerentemente o igual valor das liberdades políticas a não ser como equiparação quanto aos meios de influência, parece surgir uma contradição na teoria de Rawls. Isso porque, novamente, todas as desigualdades de influência na política têm suas raízes em desigualdades econômicas e sociais. Segue-se disso que a eliminação dessas desigualdades de influência política implicaria a eliminação das desigualdades sociais que as geraram.

Ocorre que essas desigualdades socioeconômicas poderiam elas mesmas ser aprovadas pelo segundo princípio de justiça de Rawls. Se isso for verdade, então aparentemente estamos diante de um duplo paradoxo: por um lado, um conceito rawlsiano (o de igual valor das liberdades políticas) não admite ter outro conteúdo coerente com a realidade a não ser um que se opõe à ideia inicial de Rawls; e, de outro, uma desigualdade econômica que poderia ser aceita à luz do segundo princípio acabaria por gerar justamente o desnível em termos das liberdades que o primeiro princípio havia proibido. De toda sorte, torna-se impossível sustentar a prioridade lexical entre os dois.

Para que possamos efetivamente entender a existência desse paradoxo, há um argumento que se faz necessário imediatamente afastar. Trata-se do argumento segundo o qual a teoria rawlsiana excluiria as desigualdades que produziriam aquelas disparidades de influência política. Um raciocínio como esse estaria embasado em uma interpretação de Rawls que não se sustenta. É mais do que evidente que o segundo princípio não admite toda e qualquer desigualdade, mas nada leva a entender que as desigualdades por ele admitidas não possam ser consideráveis.

Em outras palavras, nada na teoria de Rawls parece sugerir que uma desigualdade não seria aceita apenas por ser grande. Uma desigualdade pode ser bastante considerável e ainda assim respeitar os dois subprincípios, da igualdade equitativa de oportunidades e da diferença. Na verdade, dependendo de qual sociedade se esteja falando, é possível inclusive que o princípio da diferença só possa ser satisfeito se a desigualdade entre um grupo e outro for muito elevada (POGGE, 2007).

Uma situação como essa não é nem mesmo difícil de conceber. Poderíamos simplesmente imaginar uma sociedade em que a agricultura fosse absolutamente essencial para todos, e apenas um décimo dos indivíduos possuísse uma aptidão excepcional para um cultivo eficiente do solo. Acrescente-se, contudo, que 
esse cultivo seja especialmente difícil, cansativo, demorado e custoso. Resguardados os mesmos direitos para todos e a mesma possibilidade de todos tentarem a carreira de agricultor, a solução rawlsiana provavelmente seria que os agricultores precisariam ter um patamar muito elevado em relação aos outros para que se sentissem suficientemente estimulados ao ofício, de modo que uma desigualdade elevada seria aceita.

Assim, posto que a teoria de Rawls regula as desigualdades, mas não impossibilita que elas sejam de dimensão considerável, as desigualdades apontadas por Scanlon não seriam prontamente excluídas apenas por serem grandes. Pelo contrário, elas poderiam perfeitamente ser aceitas, de uma maneira que tem a ver com como Rawls concebe a instituição de seus princípios de justiça.

De fato, Rawls (1971) não considera que os dois princípios, mais a regra de prioridade que controla a relação entre eles, possam ser diretamente aplicados pelas autoridades simplesmente por terem sido escolhidos a partir da posição original. Antes, eles precisam ser gradualmente introduzidos na sociedade. Primeiro, devem ser incorporados ao ordenamento jurídico como um todo, sendo acrescentados ao texto constitucional ou às normas que têm status equivalente ao de normas constitucionais.

Após isso, precisam ganhar concretude e incorporados às leis e às demais normas, até que todo o sistema já esteja plenamente regulado pela concepção de justiça que os dois princípios juntos constroem. Só então eles poderiam ganhar aplicação prática a casos concretos envolvendo distribuição de bens primários. A regra de prioridade, dentro desse processo, funcionaria como espécie de parâmetro, com base no qual a aplicação e instituição do segundo princípio é afastada se ainda o primeiro não tiver sido efetivado.

A questão é que, em um processo como esse, é possível que desigualdades como as apontadas por Scanlon surgissem e a princípio fossem reputadas como aceitáveis. Isso porque a relação entre desigualdades sociais e desigualdades de nível de influência na política é de natureza contingente, e não necessária. Assim, no curso das etapas da justiça de Rawls, primeiro os direitos e liberdades seriam todos registrados e estabelecidos de forma segura, como normas constitucionais, para que só depois o conjunto das instituições permitisse que alguns indivíduos passassem a gozar de uma parcela de renda e riqueza maior que a de outros. Essas desigualdades econômicas, uma vez permitidas, começariam a produzir paulatinamente as desigualdades problemáticas de influência na política.

A título de ilustração, poderíamos pensar em uma atividade que demandasse anos de preparo e treinamento, como a neurocirurgia. Em uma sociedade em que os indivíduos fossem iguais em direitos, e em que todos tivessem igual possibilidade concreta de se tornar neurocirurgião, a teoria rawlsiana apontaria como justa a distribuição na qual neurocirurgiões ganhassem bem mais que outras profissões, de modo que esse incentivo permitiria aos membros da sociedade gozarem de mais profissionais qualificados na área.

O problema que queríamos abordar é que o regime de remunerações diferenciadas já seria suficiente para que aqueles mais bem remunerados adquirissem poderes de influência sobre as decisões políticas em grau maior que os outros. Na prática, uma pessoa ter mais influência política que outra significa que sua opinião e seus interesses têm maior peso que os dos outros, o que por sua vez equivaleria a ter mais direitos políticos que os outros. O ponto é que essa disparidade quanto aos direitos políticos é uma desigualdade, pelo primeiro princípio de Rawls, inaceitável. Em outras palavras, as desigualdades que o segundo princípio legitima teriam o condão de desfazer o esquema igualitário de direitos e liberdades instituído pelo primeiro.

Nesse sentido, está-se diante de um processo de autodestruição. A regra de prioridade de Rawls exige que a distribuição igualitária do primeiro princípio seja respeitada para que qualquer desigualdade possa surgir. Mesmo assim, contudo, algumas das desigualdades posteriormente autorizadas pelo segundo princípio têm como consequência gerar um desequilíbrio que para o primeiro princípio é inadmissível, na medida em que a desigualdade de influência política seria o equivalente a alguns indivíduos possuírem mais direitos políticos do que outros. Uma vez que isso acontecesse, a relação de prioridade teria sido violada.

\section{CONCLUSÃO}

Se todos os argumentos aduzidos até aqui forem convincentes, resta concluir que existem pelo menos algumas desigualdades, aquelas quanto aos meios de informação e comunicação, que passam no crivo de Rawls para desigualdades socioeconômicas, conforme fixado no segundo princípio, mas que têm como efeito 
a violação do primeiro princípio de justiça, que em tese deveriam respeitar. Em última instância, isso poderia significar a necessidade de uma atualização dos princípios de justiça rawlsianos, para que eles se tornassem capazes de dar conta desse fenômeno.

Não se trata de dizer, contudo, que Scanlon refutou Rawls por completo, ou que evidenciou a total inutilidade de suas proposições. Em verdade, o que ocorre é que a forma de abordagem de Scanlon, que se situa muito mais no terreno de ética prática, consegue apresentar um maior aprofundamento em questões particulares. Como foi possível observar na argumentação desenvolvida, isso deve-se ao fato de que Scanlon se diferencia metodologicamente de Rawls na medida em que todas as suas análises são construídas a partir de informações empiricamente constatáveis a respeito das sociedades capitalistas ocidentais.

Nesse sentido, a contribuição que se pretendeu dar com este artigo foi muito mais no sentido de uma tentativa de identificar de que forma teorias normativas formuladas a partir de abstrações - em Rawls, a posição original - podem encontrar certas dificuldades ao se aplicarem a casos particulares. Em se tratando de uma abordagem normativa como a justiça como equidade, é seguro afirmar que problemas de aplicação prática dessa natureza sejam reflexos do fato de a teoria em si ser elaborada por meio de uma metodologia essencialmente baseada em raciocínios abstratos.

Uma deficiência dessa natureza só poderia ser resolvida por uma teoria da justiça que já fosse, desde suas premissas iniciais, pautada em um diagnóstico a respeito das formas de dominação historicamente presentes na sociedade à qual ela se aplicaria. Ou seja, uma teoria temporalmente situada e sociologicamente enriquecida, de modo a possuir o potencial crítico de captar eventuais injustiças que poderiam advir da concretização de seus princípios.

\section{REFERÊNCIAS}

AUDARD, C. John Rawls. London: Acumen Publishing, 2007.

CONSTANT, B. Da liberdade dos antigos comparada à dos modernos: discurso pronunciado no Ateneu de Paris em 1819. São Paulo: Edipro, 2019.

DWORKIN, R. Rights as Trumps. In: WALDRON, J. (org.). Theories of Rights. Oxford: Oxford University Press, 1985.

FREEMAN, S. Original Position. Stanford Encyclopedia of Philosophy. 1996. Disponível em: https://plato.stanford.edu/entries/ original-position/. Acesso em: 20 jul. 2019.

FREEMAN, S. Rawls. New York: Routledge, 2007.

GARGARELLA, R. As Teorias da Justiça depois de Rawls: um breve manual de filosofia política. São Paulo: Martins Fontes, 2008. HART, H. L. A. Rawls on Liberty and its Priority. The University of Chicago Law Review, Chicago, v. 40, n. 3, p. 534-535, 1973.

KANT, I. Fundamentação à metafísica dos costumes. Lisboa: Edições 70, 2007.

LEUNG, K. W. Why Does Inequality Matter? T. M. Scanlon. Journal of Applied Philosophy. 2018. Disponível em: https://onlinelibrary.wiley.com/doi/abs/10.1111/japp.12338?af=R. Acesso em: 19 jul. 2019.

MULGAN, T. Utilitarismo. Petrópolis, RJ: Vozes, 2012.

POGGE, T. John Rawls: His Life and Theory of Justice. Oxford: Oxford University Press, 2007.

RAWLS, J. A Theory of Justice. Cambridge: The Belknap Press, 1971.

RAWLS, J. Justice as Fairness. Philosophical Review, Durham, v. 67, n. 2, p. 164-194, abr. 1958.

RAWLS, J. Distributive Justice: Some Addenda. The American Journal of Jurisprudence, South Bend, v. 13, n. 1, p. 51-71, jun. 1968.

SCANLON, T. Why Does Inequality Matter. Oxford: Oxford University Press, 2018.

SCANLON, T. Rawls' Theory of Justice. University of Pennsylvania Law Review, Philadelphia, v. 120, n. 5, p. 1.020-1.069, 1973.

ZAMBAM, N. J. Introdução à Teoria da Justiça de John Rawls. 2. ed. Rio de Janeiro: Lúmen Juris, 2016. 